\title{
Juventude brasileira, entre a tradição e a modernidade
}

Hebe Signorini Gonçalves

$\mathrm{O}$ individualismo tem sido afirmado como marca da sociedade contemporânea. A ele se submeteriam todos os protagonistas sociais, em particular os que vivem e circulam nas grandes metrópoles, açodadas pela competição e pelo consumo. Segundo esse modelo de análise, a sociedade do espetáculo, para usar o termo cunhado por Guy Debord, impõe subjetividades e forja modos de pensar, sentir e agir, sobretudo entre os jovens, segmento etário tido como o mais vulnerável aos apelos do individualismo. A juventude, na visão clássica, é entendida como "uma categoria social gerada pelas tensões inerentes à crise do sistema" (Foraccchi, 1972, p. 160); estudos contemporâneos reafirmam seus excessos pulsionais (cf. Souza, 2005) como motores da construção das formas pelas quais o jovem se apresenta à sociedade. A primeira visão acentua o conflito e a busca pela experimentação; a segunda encaminha a postura individualista e narcísica, considerada típica da sociedade e da juventude contemporâneas.

$\mathrm{O}$ interesse pela juventude desponta de tempos em tempos, mas parece contaminado sempre por esses motores. As crises e os excessos, os conflitos e as explosões que a eles se seguem, acompanham a história da preocupação social e acadêmica com a juventude. Os anos de 1920 presenciaram a explosão desse interesse na razão direta da comoção gerada pela turbulência social em Chicago; naquela época, toda uma geração de jovens italianos, judeus, irlandeses e afro-americanos tornou-se objeto de estudos da 
1. A associação entre juventude e criminalidade inspirou políticas públicas também no Brasil, onde "as primeiras estatísticas sobre a criminalidade juvenil já anunciavam seu aumento" (Santos, 2004, p. 216). Ao registrar essa curiosa constatação, a autora oferece indícios de que também no Brasil a preocupação com a juventude se calca em intentos de regulação social. sociologia, em busca de uma resposta às indagaçóes acerca de possíveis "implicações entre juventude, violência, criminalidade e desorganização social urbana" (Zaluar, 1997, p. 18) ${ }^{1}$. Premidas nos anos de 1920 pelas lutas das gangues, nos anos de 1950 pela explosão demográfica nas urbes e mais recentemente pelos elevados índices de disseminação das doenças sexualmente transmissíveis, as ciências humanas privilegiaram o exame da juventude sob a ótica do negativismo.

Os excessos juvenis, tomados como impulso da desordem urbana, colocaram em movimento esforços de disciplinarização. Associadas aos comportamentos disfuncionais, as pulsões da juventude tornaram-se foco da assepsia social que queria o controle e a correção dos vícios, e nesse percurso as ciências reforçaram ao longo dos anos a percepção de que boa parte das mazelas sociais poderia ser creditada na conta da juventude e de seus anseios de diferenciação. Firmou-se no imaginário social a associação entre a juventude e as grandes questóes de cada tempo: no século XXI, quando grassam as preocupaçôes com o individualismo exacerbado e a criminalidade crescente, o jovem emerge como individualista e responsável, em grande parte, pela criminalidade urbana.

O vínculo entre juventude e criminalidade, estabelecido pelo funcionalismo nos anos de 1920, pode ser identificado ainda hoje em textos que falam da modernidade, da globalização e da violência na vida das metrópoles, propugnando um modelo de controle da criminalidade pautado pela atenção aos pequenos delitos e aos jovens transgressores. Os textos de Wacquant (2001) ilustram bem o modo como o controle social persegue, ainda hoje, o ideal funcionalista.

Mas a multiplicidade de vivências, a diferença no desenho das cidades e as formas díspares de organização comunitária, sobretudo no Brasil, não autorizam supor a hegemonia de modelos, nem do ponto de vista da criminalidade juvenil - esta mais questionada por dados que demonstram seus equívocos -, nem do ponto de vista da preponderância do indivíduo narcísico e desenraizado. Como nossos jovens vêem a si mesmos? Como lidam com suas dificuldades, e de quais estratégias e laços sociais lançam mão para ascender ao mundo adulto?

\section{$\star \star \star$}

Começam a despontar algumas críticas à hegemonia do modelo do sujeito marcado pelo individualismo. Questionando a natureza totalizan- 
te dessa representação, Amorim (2002) argumenta que o individualismo equivale ao mito no mundo clássico, pois orienta e organiza percepçōes de mundo, numa denúncia de que ele faz circular representaçôes sociais que contribuem para produzir o que anuncia. Mais radical é Duarte (1983), para quem o individualismo poderia ser considerado a religião do mundo contemporâneo.

Segundo Boaventura Souza Santos, os fenômenos correlatos da globalização não dão conta das questôes mais prementes com as quais se batem as sociedades periféricas ${ }^{2}$. Nas ditas sociedades centrais, a globalização sucede a um Estado forte, capaz de organizar a cultura e de oferecer ao indivíduo uma referência institucional, portanto pública. Esse modelo serve às nações européias, mas não a Portugal, nem tampouco ao Brasil, países em que o espaço doméstico tinha e tem um forte poder de regulação social; em ambos, é o doméstico que ancora o público e supre muitas de suas funções (cf. Santos, 1997). No Brasil, a família - e a cadeia de relações que se estrutura em torno dela - ainda é uma forte referência da subjetividade, sobretudo entre as camadas mais pobres da população. Como já mostrou Sarti (1996), as cadeias migratórias articulam-se em torno de relações de parentesco e amizade tanto no que diz respeito à busca pelo trabalho como na eleição dos locais de moradia.

Admitindo que os laços de parentesco falam da tradição cultural e contrapõem-se aos padrões pós-modernos, seria preciso admitir aqui uma permanência da tradição, tornando tensos os apelos da modernidade.

Ao descrever a vida urbana, referindo-se ao município de Curitiba, Sanchez (2001) destaca sua multiplicidade irredutível de sentidos. Lendo a cidade como um território de disputas simbólicas, de jogos e discursos em permanente confronto, a autora marca a impossibilidade de reduzi-la, e a seus cidadãos, a uma única definição. Do mesmo modo, Castro (2004, p. 24) descreve a urbe como a geografia do múltiplo e do variado, lugar que acolhe uma "coletividade de indivíduos singulares na qual todos têm o direito de buscarem suas vias de expressão pessoal”. Referindo-se mais diretamente às vivências da juventude, Pais (2003) acentua o cruzamento das trajetórias de vida que a cidade proporciona, sucessivamente aproximando e afastando estranhos, tecendo cadeias de relaçôes que ele chama de interconectividade típica da juventude. Mas se é verdade que o jovem experimenta, circula, troca de lugares e de afetos, é preciso reconhecer também que ele organiza essas trocas segundo a lógica própria com que persegue os sentidos na cidade. Como lembra Carrano:
2. De acordo com Santos (1997), essa expressão aplica-se a nações como Portugal e Brasil, onde as relaçōes entre sociedade civil, Estado e mercado se regem segundo hierarquias pouco suscetíveis de globalização. 
Até mesmo nos grupos com forte identificação gregária, onde as trajetórias dos sujeitos se cruzam intensamente, existem processos que fazem com que os seus membros se distanciem por outras redes de significados, configurando as variadas possibilidades de vínculos sociais que podem ser tramados nas cidades (2001, p. 16).

Os centros urbanos brasileiros, marcados pelas enormes distâncias sociais, põem em contato territórios informados pelo simbólico e permeados pelo econômico. Nesse particular, nossa geografia urbana impóe experiências que diferem de qualquer cidade das sociedades centrais. A disparidade de renda, a presença ou ausência das benfeitorias sociais e a maior ou menor dificuldade de acesso às benesses são os elementos mais visíveis da rede de significados que o jovem deve aprender a decodificar. A convivência com o outro, na interconectividade das histórias vividas, mostra que uns têm acesso amplo ao conjunto de benfeitorias sociais, outros renunciam a elas e alguns se apropriam daquelas que lhes parecem indispensáveis. Assim, o jovem é chamado a construir ativamente as redes de significado, sob pena de sucumbir aos apelos do estranho e aos perigos da cidade. Nessa posição, que é necessariamente ativa, há de haver um nucleamento de sentidos passível de identificação. Como o jovem mapeia os territórios urbanos e com base em que premissas se move entre eles?

A visibilidade mais ou menos explícita da distância entre os diversos grupos sociais que convivem no meio urbano - e as formas como essas distâncias são preenchidas - não é um problema menor, já que toca a temática da regulação. Castro (2001) argumenta que a ocupação da cidade por crianças e jovens só é bem-vinda quando feita nos limites da ordem prevista pelo adulto, que submete e controla o ir-e-vir do jovem pelas cidades. Para a autora, a regulação também contém seus excessos, e ela interpreta como agressão e violência o que é busca de sentido e vontade de participação. A pichação, com a qual o jovem quer imprimir sua marca pessoal às ruas da cidade, e a zoação, o desafio do outro por meio da galhofa e do desacato, são exemplos de atitudes comuns aos jovens, que, se contêm um viés de agressão, são também formas de reivindicação: “[...] o chamamento do outro, para que preste atenção e se volte para aquele que zoa, que reclame, que tome uma posição e que ponha limites. Na verdade, zoar pode se tornar uma forma desesperada e última de estabelecer vínculo" (Castro, 2004, p. 121).

Esse atravessamento de sentidos, em que o desejo de diferenciação do jovem se confronta com os anseios de regulação e controle próprios da or- 
dem social instituída e adulta, ganha contornos típicos numa sociedade em que a regulação se exerce a partir do doméstico. Diante da tibieza das instituições, cabe à família, e àqueles que lhe são próximos, promover em primeira instância a regulação da conduta. Como a família dará conta dessa função reguladora cujo alcance deve exceder o doméstico?

\section{O jovem fala de si}

Em pesquisa coordenada por Castro et al. (2005), 1.300 jovens foram entrevistados na região metropolitana do Rio de Janeiro ${ }^{3}$. Entre outros aspectos, eles foram indagados acerca de quais seriam, em seu entender, os principais problemas da juventude, e quais as formas de enfrentá-los.

Os resultados mostram que as questôes relacionadas à violência, à droga e ao tráfico despontam como os principais problemas citados. Na descrição dos jovens, é a associação violência-droga-tráfico a resposta mais significativa. Observe-se que não se trata de problemas isolados que se potencializam, mas de uma única questão expressa em três vertentes indissociáveis, constituindo uma unidade discursiva. No entender dos jovens entrevistados, violência-droga-tráfico constitui um problema porque impõe um risco real - a ameaça à segurança pessoal - e uma limitação simbólica - representada no sentimento do medo que conforma os modos de viver e circular na cidade.

Não há como escapar: polícia e traficantes aparecem como faces do mesmo problema; amigos de antes ingressam na marginalidade e não podem mais compartilhar espaços nem tampouco histórias de vida; freqüentar os bares, os pontos de encontro, é atitude que requer um esmiuçar constante dos riscos envolvidos; a ida à escola deve considerar, a cada dia, se é possível ir, ficar e voltar. A praça, que nas comunidades mais pobres é o lugar da vida social, nem sempre está disponível para a brincadeira, o namoro, o encontro com os amigos. Assim descrita, a vida nas comunidades emerge como o lugar de uma forma bastante peculiar de socialização, em que será necessário ao jovem exercitar a percepção, ficar esperto ${ }^{4}$ para escapar das inúmeras armadilhas que as trocas sociais oferecem. É preciso resistir à tentação do ganho fácil, empreender um esforço da vontade para aplicar-se nos estudos e formar um capital pessoal que mais adiante, transpostos os muitos obstáculos, possa vir a garantir um emprego que permita ao jovem apresentar-se à sociedade, finalmente, como adulto.
3. Os resultados são apresentados em Castro et al. (2005). No presente texto, são explorados apenas alguns dos itens investigados. São também discutidos dados parciais, relativos a uma das comunidades estudadas, $\mathrm{o}$ bairro de Bom Retiro, no município de Duque de Caxias. Esta comunidade é destacada porque constitui um núcleo onde o tráfico de drogas não é atuante e não domina as relações sociais.

4. Todas as frases e expressões em itálico ao longo deste item e do próximo são transcritas das entrevistas e correspondem aos termos empregados pelos jovens e por seus familiares. 
O destaque aos dados coletados na comunidade de Bom Retiro serve para desmistificar a crença de que a violência decorre das atividades ligadas ao tráfico de drogas. Ali não há referência ao tráfico, mas, ainda assim, a droga é o problema mais citado; ela se conecta à violência pela via subjetiva, não pelas disputas de quadrilha pelo mercado da droga. No entender dos jovens residentes nessa comunidade em particular, o uso de drogas é uma escolha do sujeito, condicionada em grande parte pelos problemas que ele não quer ou não pode enfrentar: porque tem a cabeça fraca ou porque, diante das dificuldades com os pais em casa, elegeu a droga como uma resposta fácil para seus problemas. $\mathrm{O}$ julgamento moral que condena o uso da droga será aplicado, assim, às consequiências que ela acarreta para o sujeito: a droga impede a dedicação aos estudos, esforço necessário na construção de um futuro estruturado com base no emprego sólido e nas relações afetivas estáveis. A droga compromete as relaçôes de amizade e vizinhança, pois, drogado, o jovem se sente superpoderoso e quer matar todo mundo. Ao deslocar o tráfico, pode-se assim pôr em relevo as escalas de valor que orientam certas percepções do jovem: o núcleo de sentido em suas falas é a cabeça fraca, que afasta o jovem do emprego e da vida em família, e introduz a violência na esfera de suas relaçóes pessoais. Mais que a segurança pessoal, preocupa o comprometimento de projetos de futuro que têm como rumo e norte a estabilidade econômica e afetiva. Consciente das dificuldades a superar para realizar esses projetos, o jovem deixa transparecer que só a cabeça forte o levará até lá.

Não se trata de negar o risco das ruas, reconhecido como real. Todos os entrevistados fazem referência a uma violência que é difusa, que está em todo lugar, que alimenta seus medos e condiciona suas escolhas. O enfrentamento dessa dificuldade específica pede a ação dos setores públicos, em particular da polícia, instância que identificam como a responsável pelo controle da criminalidade urbana. Mas, incontinenti, apontam a polícia como parte do problema, pois ela é corrupta, entra nas comunidades pra esculachar, estabelecendo uma tensáo que potencializa o medo e a violência, em vez de reduzi-los.

$\mathrm{Na}$ ausência do público como fonte de suporte para a vida social até mesmo no que diz respeito ao controle da criminalidade, o jovem ressente-se da ausência do Estado. Diante de um poder público que não tem feito muita coisa, refluem sobre a família todas as expectativas de suporte e apoio. Não faço a minima idéia de com quem ele [o jovem] pode contar hoje além da família, resume um entrevistado. 
$\mathrm{Na}$ frase a família é tudo, repetida por um contingente expressivo de jovens entrevistados, desenha-se a chave da construção de suas subjetividades. $\mathrm{O}$ apoio da família, vital para ampliar a chance de realizar os projetos de vida, é praticamente o último reduto de seus sonhos. É um apoio que se traduz na presença - conversar, acompanhar a vida dos jovens e ser companheiro nos momentos difíceis - e também no esteio econômico que permite atravessar a fase da vida em que não podem se sustentar.

Vê-se, assim, que o jovem brasileiro atribui à família expectativas que nas sociedades centrais são compartilhadas por outras instâncias sociais; a retração do público reforça o privado e faz com que repousem no sujeito e no núcleo familiar as forças de agregação social. Nesse sentido, não surpreende que as escolhas sejam interpretadas sob um viés voluntarista - o porque quer - orientado pelo caráter construído nas relações privadas. Não surpreende tampouco que, convidados a enumerar as pessoas que mais admiram, os jovens construam uma lista encabeçada pela mãe, descrita como uma lutadora. A idealização da figura materna, a idealização da vida familiar como esteio do próprio futuro e as expectativas lançadas sobre a família como fonte de apoio são fatores que produzem dois efeitos: em primeiro lugar, abrem caminho para que os valores cultivados pelos pais sejam aceitos como pilares do caráter; já vimos, nas expressões cabeça forte e em seu contraponto, a cabeça fraca, como os jovens indicam que compartilham esses valores. O segundo efeito fala da carga de expectativas lançadas sobre a geração passada, que faz das mães e dos pais as âncoras isoladas dos processos de socialização. Como a família brasileira lida com elas?

\section{O família fala de si, e do jovem}

Dados de pesquisa acerca da violência familiar no Brasil sugerem que o espaço doméstico não é caixa de ressonância, mas lugar organicamente articulado ao social, recebendo sua influência e produzindo efeitos sobre ele (cf. Gonçalves, 2003).

O discurso de trinta mães, entrevistadas aproximadamente na mesma base geográfica dos jovens cujos depoimentos foram mencionados no item anterior, indica o uso amplo da punição corporal com propósitos disciplinares. As entrevistadas defendem essa prática quando regulada por limites ditados pela cultura. A essas formas punitivas, aplicadas segundo os parâmetros que as regulam, as mães recusam dar o rótulo de violentas. Elas discordam, assim, da interpretação dominante que atribui ao uso da força 
física um efeito pernicioso na formação e no desenvolvimento de crianças e jovens.

Para efeito deste texto, é importante destacar os motivos que, do ponto de vista das entrevistadas, justificam o uso da punição corporal. Adotada como recurso extremo, ela é empregada em situações nas quais a criança ou mesmo o jovem, apesar de advertidos, insistem na desobediência ou no desrespeito aos pais ou mesmo aos mais velhos com os quais mantêm relações de parentesco ou vizinhança. As mães entendem que a obediência à hierarquia entre as gerações é o pilar nas relações sociais, pois é o respeito ao próximo que produz o assujeitamento necessário à transmissão de valores e à formação do caráter.

Mais preocupadas com a violência na rua do que com os excessos disciplinares domésticos, as mães entrevistadas nomeiam uma violência que está em todo lugar e faz com que se mate por um real, ou por nenhum. Elas invocam a atração que a marginalidade fora de controle exerce sobre o jovem e o apelo contemporâneo pela afirmação da singularidade e da diferença como armadilhas da convivência entre estranhos, características incontornáveis da vida na cidade. Reconhecendo que é impossível negar a liberdade, e que seus filhos cedo ou tarde serão confrontados com os desafios da cidade, as mães entendem que a tarefa de educar tem como propósito central a boa formação, o caráter, a cabeça forte.

Essas expressôes condensam sentidos: a boa formação não se restringe à obediência no espaço doméstico, mas fala principalmente do comportamento adequado na rua, que abarca as relaçóes respeitosas para com os mais velhos, a escolha adequada das amizades, o empreendimento de esforços na escola, a esquiva dos grupos envolvidos com drogas, criminalidade ou qualquer forma de violência. A relação dos problemas a serem evitados indica a preocupação das mães com a reconstrução da sociabilidade no espaço público. Indica, além disso, que assumem como sua essa tarefa; a frase de uma das entrevistadas não deixa margem a dúvida: as pessoas que estão na rua, violentando, atacando as pessoas, ela tem uma criação, né, então começa em casa. Se você cria seus filhos na paz, eles vão sair lá fora e não vão atacar ninguém.

Haveria elo de ligação entre a criminalidade urbana e a violência familiar? Com base em dados produzidos nos Estados Unidos, Gelles (1997) afirma que tanto o comportamento violento como a conduta criminal são conseqüências comprovadas do abuso sofrido na infância. No Brasil, essa associação é posta em dúvida pelas mães que entrevistei. No primeiro mo- 
mento, elas negam qualquer conexão com base em suas histórias pessoais: se fosse assim - declarou uma das mães -, eu também tinha sido bandida. A seguir, elas invertem a relação causal e afirmam que a punição corporal, aplicada quando requerida, contribui para forjar o caráter, tarefa doméstica por excelência: abandonado, o mundo ensina. [...] se a gente largar assim demais, é o mundo que vai ensinar. E o mundo vai ensinar errado.

Não deixa de soar estranha essa crença na possibilidade de controle da desordem urbana a partir do doméstico. Durante longo tempo, essa justificativa para a defesa da punição corporal foi interpretada como mero argumento para validar a prática dos castigos físicos, essa sim condenável. Mas o julgamento moral precipitado dessa linha de argumentação tem furtado ao exame os fatores que informam a inclinação da família brasileira pelo uso da punição corporal. Trata-se de um procedimento que não é gratuito, nem espontâneo.

Ele tem origem nos preceitos higienistas, que associaram a disciplina doméstica ao controle dos sujeitos no espaço público. Lopes Trovão proclamava a infância como o período em que se forja "a gênese da humanidade mais perfeita”. Belisário Penna via na educação doméstica o dispositivo capaz de assegurar a ordem sem o uso da força. Para Lourenço Filho, a educação doméstica - mais até que o Estado - seria capaz de "guiar as liberdades" das crianças de modo a evitar "escolhas passionais e caprichosas" (cf. Corrêa, 1997). Repetindo esses princípios à exaustão, o higienismo ensinou que a lógica do universo familiar e a lógica da cidade se fundem numa ligação de simbiose e dependência da qual a relação mãe-filho é adubo e semente (cf. Costa, 1989). Até os anos de 1930, o higienismo incutiu a crença de que à mãe cabe evitar o ócio, a delinqüência e o vício da rua. Hoje, setenta anos mais tarde - ou no espaço de duas gerações -, as mães flagram-se isoladas nessa tarefa, sem contudo renunciar a ela.

Sem contar com a orientação de ninguém, confiando no vivido para tomar decisões cruciais no cotidiano, as mães oferecem os elementos que permitem compreender a permanência da racionalidade higienista. Em vez da família moderna acossada pelos técnicos, sitiada pelo saber da ciência e destituída da função de educar, típica das sociedades centrais (cf. Lasch, 1991), a mãe brasileira queixa-se sobretudo da solidão, da falta de amparo e de assistência. Assistindo impotente ao crescimento da criminalidade, ela crê que pode proteger seus filhos das ameaças do público, e acredita na possibilidade de disciplinar o social a partir do doméstico. Entende-se assim por que a família brasileira se mantém como elemento cen- 
tral nos processos de regulação social. A despeito da eficácia questionável das práticas educativas, é mister reconhecer que elas empreendem um esforço em nome do coletivo. A despeito da condenação moral dessas práticas, amplamente calcadas na punição corporal, é mister reconhecer também que seus filhos, ao ecoar suas frases e expressões e ao anunciar a família como único suporte com que contam, contribuem para referendar sua crença e imprimir-lhe algum grau de eficácia.

\section{Interconectividade}

Norbert Elias já disse que, em estágios mais primitivos do desenvolvimento social, quando o Estado ainda não se estruturou de modo a cumprir com as atribuições que a modernidade lhe destina, o indivíduo cultiva laços mais estreitos de parentesco. Isso ocorre porque, na ausência do Estado, a família é a unidade capaz de prover ajuda e proteção nas situaçôes de necessidade. $\mathrm{Na}$ ausência da intermediação do Estado, a família arca com a responsabilidade de transmitir os valores sem os quais uma sociedade não pode ser entendida como tal. Não se trata de discutir se os métodos, públicos ou privados, são ou não adequados ao propósito de adaptar a criança à vida em sociedade; não se trata tampouco de discutir o grau de satisfação e felicidade do indivíduo nesse processo. A discussão dos laços entre indivíduo e sociedade visa, antes, a compreender os processos pelos quais um e outra se conformam mutuamente (cf. Elias, 1994).

O texto de Norbert Elias, cuja versão original data de 1987, não se batia ainda com as questóes colocadas pela sociedade pós-moderna. Em escritos datados dos anos de 1950, Hannah Arendt antecipava as questóes propostas por Elias e afirmava que o social, quando visto como locus de proteção, segurança e acolhimento dos afetos, é destituído de seu caráter político. Discutindo a aplicação do pensamento de Arendt à cidade de São José dos Campos neste início de século, Cesar (2001) mostra que a violência, ao trazer a ameaça e o perigo aos nossos centros urbanos, força um comportamento que quer evitar tudo o que é estranho, bloqueando a alteridade e despolitizando o mundo.

A destituição do político, por outro lado, é apontada por Almeida e Almeida (2004) como produto de um Estado que continuadamente se exime da distribuição das benesses sociais. A própria relevância que o senso comum atribui à violência se conecta ao abandono da coisa pública, que termina por encarregar os sujeitos de prover por si mesmos a justiça e a segu- 
rança. Nas comunidades pobres, que não dispõem de recursos políticos ou econômicos para suprir a ausência do Estado, esse enfrentamento da violência dar-se-á a partir da cadeia relacional, em que a família é unidade basilar.

Não surpreende, portanto, que os jovens entrevistados, grande parte deles oriundos de comunidades pobres, anunciem a família como sua mais relevante referência identitária. Ao fazê-lo, eles indicam que reconhecem e valorizam os esforços dos pais em prol de sua geração. Ao enaltecer a garra dos pais no esforço cotidiano pelo sustento da casa e dos membros do núcleo familiar, os jovens constroem canais de troca no espaço doméstico e indicam certa receptividade ao conjunto de valores da geração anterior, o que pode ser indício de sua disposição em compartilhá-los.

No discurso dos pais, não foram buscados elementos de aceitação ou recusa do respeito e da obediência, valores que eles descrevem como centrais da tarefa educativa. Mas o reconhecimento dos jovens pelas figuras paterna e materna, elevadas à condição de ideal, e seus próprios projetos de vida, estruturados em torno da constituição do núcleo familiar, também idealizado, autorizam supor que a família segue sendo o pólo de aglutinação social no Brasil, neste início de século XXI. O encontro dos discursos na expressão cabeça fraca, entendido como a falta de caráter que abre caminho para a marginalidade e a violência, mostra que há intercâmbio no discurso dessas gerações.

A solução de grupo, o enfrentamento dos problemas da juventude a partir de uma base coletiva que se constrói em torno da família, indica a possibilidade de que, nos centros urbanos nacionais, a interconectividade a que se refere Pais (2003) incorpore amigos e conhecidos que se agregam ao longo das histórias de vida. Mas a centralidade dos valores familiares, amplamente reconhecida, sugere a possibilidade de que essa interconectividade tenha um fio condutor: as relações de parentesco. Aqui, elas são a resposta possível à destituição política.

\section{Referências Bibliográficas}

Almeida, Angela Maria de Oliveira \& Almeida, Geraldo José de. (2004), "A violência na perspectiva de uma Psicologia Social do Desenvolvimento”. In: SouZA, L. \& Trindade, Z. A. (orgs.). Violência e exclusão. São Paulo, Casa do Psicólogo, pp. 105-118.

AMOrim, Maria Luisa de Aguiar. (2002), "Educação e modernidade: uma contribui- 
ção às discussões sobre o mal-estar”. Revista Mal-estar e Subjetividade, 2(1): 1744, Fortaleza.

Carrano, Paulo Cesar Rodrigues. (2001), "Jovens na cidade". Trabalho e Sociedade, 1 (1): 15-22, Rio de Janeiro.

Castro, Lucia Rabello de. (2001), "Crianças, jovens e cidades". In: Castro, L. R. (org.). Subjetividade e cidadania. Rio de Janeiro, Faperj/7 Letras.

(2004), A aventura urbana: crianças e jovens no Rio de Janeiro. Rio de Janeiro, Faperj/7 Letras.

CASTRO, Lucia Rabello de et al. (coord.). (2005), Mostrando a real: um retrato da juventude pobre no Rio de Janeiro. Rio de Janeiro, Faperj/Nau.

Cesar, Fátima Florido. (2001), "Cidade das 'tetas fartas', cidade das 'vacas magras': encontros com adolescentes em São José dos Campos". In: CASTRO, L. R. (org.). Subjetividade e cidadania. Rio de Janeiro, Faperj/7 Letras.

CorrêA, Mariza. (1997), "A cidade dos menores: uma utopia dos anos 30". In: Freitas, M. C. (org.). História social da infância no Brasil. São Paulo, Cortez, pp. 77-95. COSTA, Jurandir Freire. (1989), Ordem médica e norma familiar. 3 ed. Rio de Janeiro, Graal. Duarte, Luiz Fernando D. (1983), "O culto do eu no templo da razão". Boletim do Museu Nacional, 41: 2-27.

Elias, Norbert. (1994), A sociedade dos individuos. Rio de Janeiro, Zahar.

ForaCCHI, Marialice M. (1972), A juventude na sociedade moderna. São Paulo, Edusp.

Gelles, Richard. (1997), Intimate violence in families. 3rd ed. London, Sage.

GonÇalves, Hebe Signorini. (2003), Infância e violência no Brasil. Rio de Janeiro, Faperj/Nau.

LASCH, Christopher (1991). Refúgio num mundo sem coração. Rio de Janeiro, Paz e Terra.

PAIS, José Machado. (2003), Ganchos, tachos e biscates. Porto, Ambar.

SANCHEZ, Fernanda. (2001), "A reinvenção das cidades na virada de século: agentes, estratégias e escalas de ação política". Revista de Sociologia e Política, 16: 31-49, Curitiba.

Santos, Boaventura Souza. (1997), Pela mão de Alice: o social e o político na pósmodernidade. 4 ed. São Paulo, Cortez.

SAnTos, Erika Piedade da Silva. (2004), "(Des)construindo a menoridade”. In: GonÇalves, H. S. \& Brandāo, E. P. (orgs.). Psicologia jurídica no Brasil. Rio de Janeiro, Nau, pp. 205-248.

SARTI, Cynthia Andersen. (1996), A familia como espelho. São Paulo, Autores Associados. SouzA, Maria Laurinda Ribeiro de. (2005), Violência. São Paulo, Casa do Psicólogo. WaCQuant, Loïc. (2001), Punir os pobres: a nova gestão da miséria nos Estados Unidos. Rio de Janeiro, Freitas Bastos. 
ZaLUAR, Alba. (1997), "Gangues, galeras e quadrilhas: globalização, juventude e violência”. In: Vianna, H. (org.). Galeras cariocas: territórios de conflitos e encontros culturais. Rio de Janeiro, UFRJ, pp 17-58.

\section{Resumo}

Juventude brasileira entre a tradição e a modernidade

Dados colhidos em duas pesquisas distintas, ambas conduzidas na região metropolitana do Rio de Janeiro, são comparados com a intenção de compreender as trocas sociais entre as geraçôes. No primeiro estudo, a análise de discurso dos pais visava a descrever e entender os recursos usados na criação dos filhos e os valores cuja transmissão é considerada essencial. No segundo, jovens foram indagados sobre os principais problemas da juventude e as formas de enfrentá-los. Vistos em conjunto, esses dados mostram que a família ainda ocupa um lugar importante na socialização de crianças e jovens, pondo em questão a extensão em que a noção de individualismo pode ser aplicada à juventude brasileira.

Palavras-chave: Juventude; Família; Individualismo.

\section{Abstract}

Brazilian youth, between tradition and modernity

Data provided by two different surveys, both conducted in Rio de Janeiro, are compared in order to analyze the relations between parents and their children. The first survey provides data on how parents raise their children and which values they believe important to sustain their actions. The second survey provides data on which are the main problems youth people have to face, and how they deal with them. Brought together, they show that family values are still very important to children and youth. In conclusion, the paper indicates that individualism may not explain the main questions on Brazilian youth.

Keywords: Youth; Family; Individualism.

Texto recebido e aprovado em 28/9/2005.

Hebe Signorini Gonçalves é doutora em Psicologia e membro do Núcleo Interdisciplinar de Pesquisa e Intercâmbio para a Infância e Adolescência Contemporâneas, do Instituto de Psicologia-UFRJ. E-mail: hebesg@ism.com.br 